\title{
Determinants of influenza vaccination in hard-to-reach urban populations
}

\author{
W.K. Bryant ${ }^{\text {a,b,d }}$, D.C. Ompad ${ }^{\text {a }}$, S. Sisco ${ }^{\text {a }}$, S. Blaney ${ }^{\text {a }}$, K. Glidden ${ }^{\text {a }}$, \\ E. Phillips ${ }^{\text {e }}$, D. Vlahov ${ }^{\text {a,b,c }}$, S. Galea ${ }^{\text {a,b,f,* }}$ \\ for the Project VIVA Intervention Working Group \\ ${ }^{a}$ Center for Urban Epidemiologic Studies, New York Academy of Medicine, New York, NY 10029, USA \\ ${ }^{\mathrm{b}}$ Department of Epidemiology, Mailman School of Public Health, Columbia University, New York, NY 10027, USA \\ ${ }^{\mathrm{c}}$ Department of Epidemiology, Bloomberg School of Public Health, Johns Hopkins University, Baltimore, MD 21205, USA \\ ${ }^{\mathrm{d}}$ Columbia University College of Physicians and Surgeons, New York, NY 10032, USA \\ ${ }^{\mathrm{e}}$ New York Presbyterian Hospital, Weill Medical College, New York, NY 10021, USA \\ ${ }^{\mathrm{f}}$ Department of Epidemiology, School of Public Health, University of Michigan, Ann Arbor, MI 48104, USA
}

Available online 8 May 2006

\begin{abstract}
Objective. Influenza vaccination rates among disadvantaged minority and hard-to-reach populations are lower than in other groups. We assessed the barriers to influenza vaccination in disadvantaged urban areas.

Methods. We conducted a cross-sectional study, using venue-based sampling, collecting data on residents of eight neighborhoods throughout East Harlem and the Bronx, New York City.

Results. Of 760 total respondents, $461(61.6 \%)$ had received influenza vaccination at some point in their life. In multivariable models, having access to routine medical care, receipt of health or social services, having tested positive for HIV, and current interest in receiving influenza vaccination were significantly associated with having received influenza vaccination in the previous year. Of participants surveyed, $79.6 \%$ were interested in receiving an influenza vaccination at the time of survey. Among participants who had never previously received influenza vaccination in the past, $73.4 \%$ were interested in being vaccinated; factors significantly associated with an interest in being vaccinated were minority race, lower annual income, history of being homeless, being uninsured/underinsured, and not having access to routine medical care.

Conclusions. Participants who are unconnected to health or social services or government health insurance are less likely to have been vaccinated in the past although these persons are willing to receive vaccine if it were available.
\end{abstract}

(C) 2006 Elsevier Inc. All rights reserved.

Keywords: Influenza; Vaccination; Hard-to-reach populations; Urban; Disadvantaged

\section{Introduction}

Every year, 10-20\% of the American population falls ill with influenza (Couch, 1993), and an estimated 36,000 persons die from influenza-related complications (Thompson et al., 2003). Vaccination is known to reduce morbidity and mortality from respiratory infections that arise secondary to influenza infection (Barker and Mullooly, 1980; Fedson, 1987). Although those age 65 and older have accounted for over $90 \%$ of influenza-related

\footnotetext{
* Corresponding author. Department of Epidemiology, University of Michigan School of Public Health, 1214 South University, Room 243, Ann Arbor, MI 48104-2548, USA. Fax: +1 7349980006.

E-mail address: sgalea@umich.edu (S. Galea).
}

deaths over the past decade (Centers for Disease Control, 2005), influenza has been associated with increased incidence of upper respiratory illness, physician visits, and the number of sick days in healthy adults under 65 years of age. As such, the American College of Preventive Medicine and the CDC's Advisory Committee on Immunization Practices (ACIP) recommends annual vaccination for all persons at high risk for complications from influenza infection without a medical contraindication. This includes adults aged 65 and older as well as those with a variety of very common chronic medical conditions such as diabetes mellitus, asthma, and heart disease. Adults aged 50 to 64 have recently been added to those recommended for flu vaccination because of the significant prevalence of these highrisk conditions in that age group (Centers for Disease Control, 
2005; Bridges et al., 2000; Nichol et al., 1995). The influenza vaccination rate among persons over the age of 65 was recently reported as 66\%; this rate was lower among Hispanics (54\%) and African-Americans (48\%) than among Whites (66\%) (Centers for Disease Control, 2005). Several studies have shown, however, that influenza vaccination rates among highrisk elderly persons can be as low as $20 \%$, even in patients in health maintenance organizations (Mullooly et al., 1994; Figaro and Belue, 2005). Rates for younger persons in high-risk groups have been shown to be even lower (Figaro and Belue, 2005).

Minorities tend to have lower influenza vaccination rates than non-minorities, a disparity that exists for all age groups, including the elderly covered by Medicare, and those who are directly targeted by public health interventions (Lashuay et al., 2000; Ostbye et al., 2003; Collins et al., 1999). Although overall rates of vaccination in the elderly have been on the rise in the last decade, the disparities among ethnic groups have persisted: Hispanic elderly are less likely than white elderly to receive influenza vaccination every year and African-American elderly are even less likely (Hargraves, 2001). Differences in vaccination rates between high-risk whites and African-Americans, at any age, persist through all demographic strata, including those related to health care access and perceived health status (Egede and Zheng, 2003; Marin et al., 2002). Inner city elderly, and a large proportion of those living in disadvantaged urban neighborhoods have consistently lower rates of influenza vaccination than those not living in areas of disadvantage, even when race is taken into account (Zimmerman et al., 2003; Nowalk et al., 2004).

Although data are sparse, other hard-to-reach sub-groups such as elderly shut-ins, active injection drug users, sex workers, and undocumented immigrants may be even less likely to receive regular influenza vaccination despite high risk of morbidity and mortality secondary to influenza. A number of the medical conditions for which influenza vaccination is recommended, such as diabetes mellitus, heart disease, and asthma, are also more prevalent in these groups. In addition, low socioeconomic status urban populations are at increased risk of morbidity and mortality when immunization rates are low (Task Force on Community Preventive Services, 2000). Many members of these hard-toreach groups are at increased risk of morbidity and mortality due to influenza as a result of factors ranging from low socioeconomic status, increased risk of immunocompromise due to lifestyle, and increased incidence and prevalence of high risk comorbidities such as asthma and diabetes.

One of the goals of Healthy People 2010 is to raise the rate of influenza vaccination in high-risk adults to $60 \%$, and for institutionalized high-risk adults and all those over age 65, to $90 \%$ (Department of Health and Human Services, 2000). Attaining these goals, however, has proved a challenge for the US public health system, which has been highlighted by the national influenza vaccine shortage of 2004. In order to address the dearth of data on the topic, we aimed to assess the barriers to immunization among hard-to-reach populations in disadvantaged minority communities. Comparable assessments of personal and structural barriers to preventive health behaviors such as influenza vaccination in this population are scarce. Others have not looked at populations like this in ways that can differentiate the importance of these barriers and their effects in vaccination rates. In the recently released draft US government "Pandemic Influenza Response and Preparedness Plan," little attention is paid to the problem of persistently low influenza vaccination rates in disadvantaged populations. The draft encourages state and local government to "identify potential barriers to vaccination of racial and ethnic minority populations and develop strategies to overcome them" (Department of Health and Human Services, 2004). This study is an attempt to do that on a broader scale, to identify the relative contributions of personal factors and structural barriers to influenza vaccination in disadvantaged urban populations.

\section{Methods \\ Study population}

The communities of East Harlem and the Bronx are among the most socioeconomically disadvantaged communities in New York City. These neighborhoods also have high disease morbidity, including some of the highest HIV incidence rates in the city, as well as higher rates of asthma and diabetes mellitus than the general population of the city. Our study was carried out in three neighborhoods in East Harlem and five in the Bronx. These neighborhoods are areas of particular disadvantage across their larger boroughs. Neighborhood boundaries were defined by a process of consultation with East Harlem and Bronx community members as part of a project that will eventually distribute influenza vaccinations to marginalized groups.

\section{Subject recruitment}

This project sought to recruit members of hard-to-reach populations, not members of the general population, in each of these eight East Harlem and Bronx neighborhoods of New York City. First, we collaborated with community members to conduct ethnographic assessments on areas within these neighborhoods with high population presence of these groups. Second, we recruited participants using venue-based sampling. Our venues included places frequented by members of our study population (e.g., elderly shut-ins active injection drug users, sex workers, and undocumented immigrants), including drug outreach centers, shooting galleries, places were sex workers solicited, and meeting places for undocumented immigrants to find off-the-books employment. These more specific areas included the sites of previous research by our team using street outreach described elsewhere (Ompad et al., 2004; Diaz et al., 2001a,b). The study was approved by the institutional review board of the New York Academy of Medicine.

\section{Data collection}

In February, March and April of 2004, bilingual outreach workers approached participants in each neighborhood and administered a brief survey about participants' vaccination histories and perceived barriers to vaccination. All persons encountered during this enumeration phase were asked to complete the survey. The survey was only administered to those aged 18 or older. Participants were not paid for completing the interview. The survey instrument assessed age, gender, race, marital status, recent and lifetime homelessness, recent and lifetime hunger sources of income, history of medical conditions which would indicate influenza vaccination, history of influenza vaccination, and interest in receiving influenza vaccination. Interest in vaccination was determined by asking, "Are you interested in taking a flu shot?" Recent influenza vaccination was defined as having received a vaccination at any time during from fall of 2003 to spring of 2004. The questions on access to health care addressed insurance and type, regularity and location of access to health care, and receipt of services from government or community agencies. For those reporting more than one type of health insurance, we classified them according 
Table 1

Correlates of lifetime influenza vaccination among residents of East Harlem and the Bronx ${ }^{\mathrm{a}}$

\begin{tabular}{|c|c|c|c|c|c|c|}
\hline \multirow[t]{2}{*}{ Characteristic } & \multicolumn{2}{|c|}{ Total sample } & \multicolumn{2}{|c|}{ Ever had flu vaccine } & \multirow[t]{2}{*}{$P$ value } & \multirow{2}{*}{$\frac{\text { Adjusted odds ratio }}{(95 \% \mathrm{CI})}$} \\
\hline & $n$ & $\%$ & $n$ & $\%$ & & \\
\hline \multicolumn{7}{|l|}{ Age } \\
\hline 18 to 29 & 192 & 25.3 & 107 & 55.7 & \multirow[t]{5}{*}{0.0001} & 1.0 \\
\hline 30 to 39 & 195 & 25.7 & 106 & 54.4 & & $0.79(0.50,1.25)$ \\
\hline 40 to 49 & 186 & 24.5 & 114 & 61.3 & & $0.88(0.54,1.44)$ \\
\hline 50 to 64 & 127 & 16.8 & 95 & 74.8 & & $1.86(1.04,3.31)$ \\
\hline 65 and older & 58 & 7.7 & 45 & 77.6 & & $1.90(0.82,4.41)$ \\
\hline \multicolumn{7}{|l|}{ Gender } \\
\hline Male & 340 & 45 & 201 & 59.1 & \multirow[t]{2}{*}{0.222} & \\
\hline Female & 416 & 55 & 264 & 63.5 & & \\
\hline \multicolumn{7}{|l|}{ Racial/ethnic background } \\
\hline White & 27 & 3.6 & 17 & 63.0 & \multirow{4}{*}{0.9141} & \\
\hline Hispanic or Latino & 574 & 75.9 & 352 & 61.3 & & \\
\hline African-American & 132 & 17.5 & 84 & 63.6 & & \\
\hline Other & 23 & 3.0 & 13 & 56.5 & & \\
\hline \multicolumn{7}{|l|}{ Marital status } \\
\hline Single, never married & 390 & 51.7 & 248 & 63.6 & \multirow[t]{6}{*}{0.1479} & \\
\hline Divorced & 74 & 9.8 & 48 & 64.9 & & \\
\hline Separated & 59 & 7.8 & 35 & 59.3 & & \\
\hline Widowed & 34 & 4.5 & 26 & 76.5 & & \\
\hline Married or common law & 174 & 23.1 & 95 & 54.6 & & \\
\hline Domestic partnership & 23 & 3.1 & 13 & 56.5 & & \\
\hline \multicolumn{7}{|l|}{ Total legal income } \\
\hline No income & 191 & 25.1 & 90 & 47.1 & $<0.0001$ & 1.0 \\
\hline$\$ 1$ to $\$ 4800 /$ year & 165 & 21.7 & 115 & 69.7 & & $1.61(0.96,2.71)$ \\
\hline$\$ 4801$ to $\$ 9600 /$ year & 178 & 23.4 & 119 & 66.9 & & $1.36(0.80,2.31)$ \\
\hline$\$ 9601 /$ year and up & 183 & 24.1 & 113 & 61.7 & & $1.37(0.81,2.30)$ \\
\hline Missing & 43 & 5.7 & 31 & 72.1 & & $2.05(0.88,4.79)$ \\
\hline Housing type & & & & & & \\
\hline Homeless & 83 & 11.2 & 57 & 68.7 & 0.4802 & \\
\hline Transitional & 122 & 16.4 & 77 & 63.1 & & \\
\hline Institutional & 13 & 1.8 & 7 & 53.8 & & \\
\hline Stable & 524 & 70.6 & 317 & 60.5 & & \\
\hline Ever been homeless & & & & & & \\
\hline Yes & 285 & 38.5 & 192 & 67.4 & 0.0099 & 1.0 \\
\hline No & 456 & 61.5 & 264 & 57.9 & & $0.92(0.61,1.40)$ \\
\hline Ever hungry in past 6 mon & & & & & & \\
\hline Yes & 220 & 29.3 & 129 & 58.6 & 0.3104 & \\
\hline No & 532 & 70.7 & 333 & 62.6 & & \\
\hline Health insurance status & & & & & & \\
\hline None & 235 & 31.3 & 102 & 43.4 & $<0.0001$ & 1.0 \\
\hline Medicaid & 312 & 41.5 & 232 & 74.4 & & $1.98(1.25,3.15)$ \\
\hline Medicare & 42 & 5.6 & 32 & 76.2 & & $1.67(0.67,4.13)$ \\
\hline Private insurance/HMO & 76 & 10.1 & 40 & 52.6 & & $0.96(0.51,1.84)$ \\
\hline Other & 87 & 11.6 & 57 & 65.5 & & $1.91(1.04,3.50)$ \\
\hline Receives routine medical c & & & & & & \\
\hline Yes & 529 & 70.3 & 367 & 69.4 & $<0.0001$ & 1.0 \\
\hline No & 224 & 29.8 & 97 & 43.3 & & $0.51(0.34,0.76)$ \\
\hline Ever received health/social & iment & & & & & \\
\hline Yes & 454 & 59.9 & 314 & 69.2 & $<0.0001$ & 1.0 \\
\hline No & 304 & 40.1 & 153 & 50.3 & & $0.85(0.57,1.26)$ \\
\hline Ever received health or so & mmu & & & & & \\
\hline Yes & 269 & 35.6 & 181 & 67.3 & 0.0177 & 1.0 \\
\hline No & 487 & 64.4 & 285 & 58.5 & & $1.03(0.68,1.66)$ \\
\hline Ever injected drugs & & & & & & \\
\hline Yes & 95 & 12.6 & 67 & 70.5 & 0.0604 & 1.0 \\
\hline No & 661 & 87.4 & 400 & 60.5 & & $0.88(0.47,1.65)$ \\
\hline Injected drugs in the past & & & & & & \\
\hline Yes & 42 & 5.5 & 25 & 59.5 & 0.7835 & \\
\hline No & 717 & 94.5 & 442 & 61.6 & & \\
\hline Ever traded sex & & & & & & \\
\hline Yes & 54 & 7.2 & 38 & 70.4 & 0.1700 & \\
\hline No & 699 & 92.8 & 426 & 60.9 & & \\
\hline
\end{tabular}


Table 1 (continued)

\begin{tabular}{|c|c|c|c|c|c|c|}
\hline \multirow[t]{2}{*}{ Characteristic } & \multicolumn{2}{|c|}{ Total sample } & \multicolumn{2}{|c|}{ Ever had flu vaccine } & \multirow[t]{2}{*}{$P$ value } & \multirow{2}{*}{$\frac{\text { Adjusted odds ratio }}{(95 \% \mathrm{CI})}$} \\
\hline & $n$ & $\%$ & $n$ & $\%$ & & \\
\hline \multicolumn{7}{|l|}{ Traded sex in the past 6 months } \\
\hline No & 740 & 97.6 & 454 & 61.4 & 0.6471 & \\
\hline \multicolumn{7}{|l|}{ Ever had a hepatitis vaccine } \\
\hline Yes & 350 & 49.4 & 255 & 72.9 & $<0.0001$ & \\
\hline Positive & 33 & 4.5 & 30 & 90.9 & \multirow{3}{*}{$<0.0001$} & 1.0 \\
\hline Never tested & 203 & 27.8 & 95 & 46.8 & & $0.15(0.04,0.58)$ \\
\hline Negative & 494 & 67.7 & 323 & 65.4 & & $0.26(0.07,0.97)$ \\
\hline \multicolumn{7}{|c|}{ Medically indicated to receive flu vaccine } \\
\hline No & 411 & 54.1 & 226 & 55.0 & \multirow[t]{2}{*}{$<0.0001$} & \\
\hline Yes & 349 & 45.9 & 242 & 69.3 & & $1.36(0.95,1.95)$ \\
\hline You do not like injections & 28 & 22.4 & 12 & 42.9 & \multirow{5}{*}{$<0.0001$} & \\
\hline $\begin{array}{l}\text { You have a medical reason that } \\
\text { conflicts with getting a vaccine }\end{array}$ & 13 & 10.4 & 9 & 69.2 & & \\
\hline You are not at high risk & 24 & 19.2 & 2 & 8.3 & & \\
\hline You already had vaccine this year & 19 & 15.2 & 18 & 94.7 & & \\
\hline Other & 20 & 16.0 & 12 & 60.0 & & \\
\hline
\end{tabular}

a Due to missing values, the numbers in some of the cross tabulations presented in this table may not add up to the total sample size.

to the more generous insurance program. Questions about vaccination included in the survey were (i) history of recent immunizations, (ii) key perceived barriers to obtaining vaccination, (iii) primary reasons for accepting or not accepting vaccination, and (iv) principal health conditions, including morbidity and factors that determine eligibility for influenza vaccination.

\section{Statistical methods}

We summarized socio-demographic variables, access to health care, drugrelated and sex-related risk behaviors, vaccination history, HIV status, interest in receiving an influenza vaccination, and, if they were not interested in influenza vaccination, their reasons for non-interest. We calculated the total number and proportion of the sample that had ever had an influenza vaccination, and used chi-square tests when comparing vaccination status by covariates to assess significance in the differences between those who had ever had an influenza vaccination and those who had not. We used logistic regression to assess relations between the above characteristics and the likelihood of ever having received an influenza vaccination. All covariates that were significantly associated $(P<0.1)$ with receiving an influenza vaccination in bivariate analysis were included in multivariate models.

We calculated the total number and proportion of the sample that had their influenza vaccination in the past year (Fall 2003 to Spring 2004) or prior to the past year (before Fall 2003), and used chi-square tests when comparing vaccination status by covariates to assess significance in the differences between the two groups. We used logistic regression to assess relations between the covariates of interest and the likelihood of having received an influenza vaccination in the past year. All covariates that were significantly associated $(P<0.1)$ with receiving an influenza vaccination in bivariate analysis were included in multivariate models.

We examined the characteristics of those who were not interested in an influenza vaccination at the time of the survey, and their reasons. We excluded those who did not want the vaccine because they had had it during the current influenza season. We calculated the total number and proportion of this subsample who were interested in having an influenza vaccination and those who were not, and used chi-square tests when comparing vaccination status by covariates to assess significance in the differences between the two groups. We used logistic regression to assess relations between the covariates of interest and the likelihood of wanting influenza vaccination at the time of the survey. Finally, we assessed reasons for not being interested in influenza vaccination among those who had never had an influenza vaccination. We calculated the total number and proportion of the sub-sample who were not interested because they felt the vaccine was not safe, because they hate injections or needles, because they had a medical reason that would conflict with receiving the vaccine, and because they perceived themselves to be at low risk. We used chi square tests to assess significance in the differences among the groups.

\section{Results}

Among 760 respondents surveyed, 468 (61.6\%) had ever had an influenza vaccination. Table 1 shows the characteristics and bivariate correlates of having ever had an influenza vaccination. Of the $61.6 \%$ of this sample who had ever had an influenza vaccination, $51.4 \%$ were vaccinated in the last year (Fall 2003Spring 2004) (data not shown). When asked if they were interested in having an influenza vaccination at the time of the survey, $79.6 \%$ of all respondents said they were. Among those who were not interested in receiving an influenza vaccine, $16.8 \%$ said it was because they did not think the vaccine was safe, $22.4 \%$ said it was because they hate injections, $10.4 \%$ said it was because they had a medical contraindication to the influenza vaccination, and $19.2 \%$ said it was because they felt they were at low risk. Other reasons for not wanting the vaccine comprised the remaining $30.2 \%$ of responses.

Sociodemographic covariates significantly associated with greater likelihood of having ever received an influenza vaccination were older age $\mathbf{7 7 . 6 \%}$ for age group 65 and older, $74.8 \%$ for age group 50-64, 61.3\% for age group 40-40, 54.4\% for age group 
Table 2

Correlates of recent influenza vaccination among hard-to-reach residents of East Harlem and the Bronx who have previously received influenza vaccination ${ }^{\text {a }}$

\begin{tabular}{|c|c|c|c|c|c|c|}
\hline \multirow[t]{2}{*}{ Characteristic } & \multicolumn{2}{|c|}{ Total } & \multicolumn{2}{|c|}{$\begin{array}{l}\text { Last shot this } \\
\text { year }\end{array}$} & \multirow{2}{*}{$\frac{P \text { value }}{\%}$} & \multirow{2}{*}{$\begin{array}{l}\text { Logistic regression model for recent } \\
\text { influenza vaccination adjusted odds ratio } \\
(95 \% \mathrm{CI})\end{array}$} \\
\hline & $n$ & & $n$ & & & \\
\hline \multicolumn{7}{|l|}{ Age } \\
\hline 18 to 29 & 92 & 22 & 40 & 43.5 & \multirow[t]{5}{*}{0.3897} & \\
\hline 30 to 39 & 94 & 22.4 & 48 & 51.1 & & \\
\hline 40 to 49 & 102 & 24.3 & 53 & 52.0 & & \\
\hline 50 to 64 & 91 & 21.7 & 52 & 57.1 & & \\
\hline 65 and older & 40 & 9.6 & 23 & 57.5 & & \\
\hline \multicolumn{7}{|l|}{ Gender } \\
\hline Male & 180 & 43.2 & 92 & 51.1 & \multirow[t]{2}{*}{0.9410} & \\
\hline Female & 237 & 56.8 & 122 & 51.5 & & \\
\hline \multicolumn{7}{|l|}{ Racial/ethnic background } \\
\hline White & 17 & 4.1 & 5 & 29.4 & & \\
\hline Hispanic or Latino & 319 & 76.3 & 169 & 53.0 & \multirow[t]{3}{*}{0.289} & \\
\hline African-American & 69 & 16.5 & 36 & 52.2 & & \\
\hline Other & 13 & 3.1 & 6 & 46.2 & & \\
\hline \multicolumn{7}{|l|}{ Marital status } \\
\hline Single, never married & 217 & 51.9 & 104 & 47.9 & \multirow[t]{6}{*}{0.0856} & 1 \\
\hline Divorced & 44 & 10.5 & 24 & 54.5 & & $1.07(0.51,2.23)$ \\
\hline Separated & 32 & 7.7 & 18 & 56.3 & & $1.05(0.46,2.40)$ \\
\hline Widowed & 25 & 6 & 17 & 68.0 & & $1.93(0.74,5.00)$ \\
\hline Married or common law & 88 & 21.1 & 42 & 47.7 & & $0.96(0.55,1.67)$ \\
\hline Domestic partnership & 12 & 2.9 & 10 & 83.3 & & $5.00(0.95,26.12)$ \\
\hline \multicolumn{7}{|l|}{ Total legal income } \\
\hline No income & 76 & 18.1 & 35 & 46.1 & \multirow[t]{5}{*}{0.6863} & \\
\hline$\$ 1$ to $\$ 4800 /$ year & 110 & 26.2 & 58 & 52.7 & & \\
\hline$\$ 4801$ to $\$ 9600 /$ year & 105 & 25 & 57 & 54.3 & & \\
\hline$\$ 9601 /$ year and up & 104 & 24.8 & 51 & 49.0 & & \\
\hline Missing & 25 & 6 & 15 & 60.0 & & \\
\hline Housing type & & & & & & \\
\hline Homeless & 53 & 12.8 & 21 & 39.6 & 0.3732 & \\
\hline Transitional & 70 & 16.9 & 31 & 44.3 & & \\
\hline Institutional & 7 & 1.7 & 4 & 57.1 & & \\
\hline Stable & 284 & 68.6 & 145 & 51.1 & & \\
\hline Ever been homeless & & & & & & \\
\hline Yes & 177 & 43.1 & 99 & 55.9 & 0.088 & 1 \\
\hline No & 234 & 56.9 & 111 & 47.4 & & $0.76(0.47,1.23)$ \\
\hline Ever hungry in past 6 mon & & & & & & \\
\hline Yes & 121 & 29.1 & 60 & 49.6 & 0.6277 & \\
\hline No & 295 & 70.9 & 154 & 52.2 & & \\
\hline Health insurance status & & & & & & \\
\hline None & 82 & 19.7 & 33 & 40.2 & 0.0784 & 1 \\
\hline Medicaid & 218 & 52.4 & 122 & 56.0 & & $1.14(0.61,2.14)$ \\
\hline Medicare & 30 & 7.2 & 14 & 46.7 & & $1.07(0.40,2.86)$ \\
\hline Private insurance/HMO & 35 & 8.4 & 22 & 62.9 & & $2.20(0.88,5.51)$ \\
\hline Other & 51 & 12.3 & 24 & 47.1 & & $1.22(0.54,2.74)$ \\
\hline Receives routine medical c & & & & & & \\
\hline Yes & 335 & 80.5 & 189 & 56.4 & 0.0002 & 1 \\
\hline No & 81 & 19.5 & 27 & 33.3 & & $0.48(0.26,0.88)$ \\
\hline Ever received health/social & nt age & & & & & \\
\hline Yes & 288 & 68.6 & 150 & 52.1 & 0.6917 & \\
\hline No & 132 & 31.4 & 66 & 50.0 & & \\
\hline Ever received health/social & nity as & & & & & \\
\hline Yes & 165 & 39.5 & 92 & 55.8 & 0.1773 & \\
\hline No & 253 & 60.5 & 124 & 49.0 & & \\
\hline Injected drugs in the past & & & & & & \\
\hline Yes & 22 & 5.3 & 18 & 81.8 & 0.0033 & 1 \\
\hline No & 397 & 94.8 & 197 & 49.6 & & $0.17(0.04,0.80)$ \\
\hline Ever traded sex & & & & & & \\
\hline Yes & 32 & 7.7 & 15 & 46.9 & 0.6007 & \\
\hline No & 385 & 92.3 & 199 & 51.7 & & \\
\hline
\end{tabular}


Table 2 (continued)

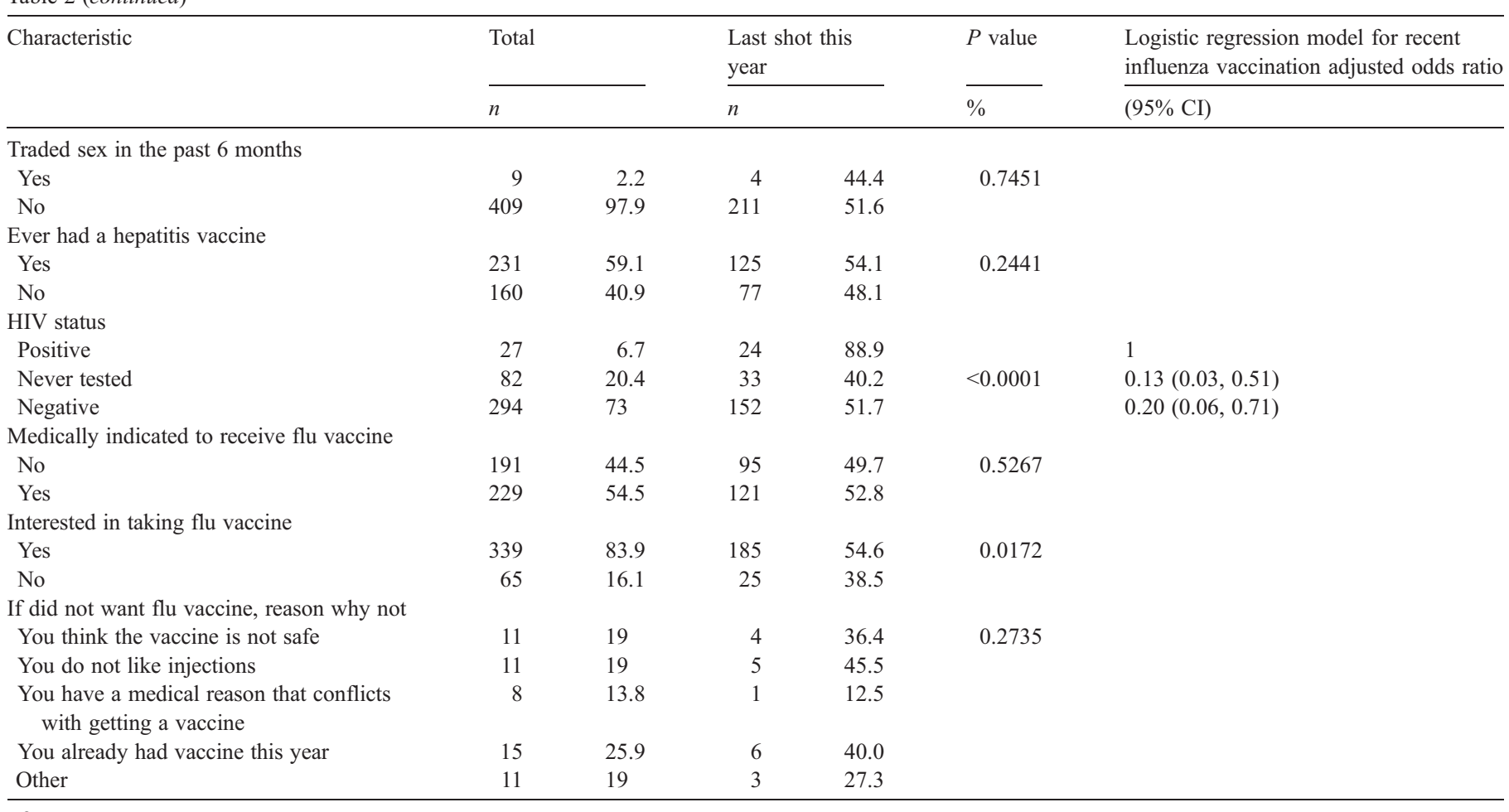

a Due to missing values, the numbers in some of the cross tabulations presented in this table may not add up to the total number of participants in this table's subset.

$30-39$, and $55.7 \%$ for age group $18-29 ; p=0.001$ ), higher total legal annual income $(69.7 \%$ for those earning $\$ 1-\$ 4800,66.9 \%$ for those earning $\$ 4801-\$ 9600$, and $61.7 \%$ for those earning $\$ 9601$ or more vs. $47.1 \%$ for those with no income; $P<0.001$ ), and having ever been homeless $(67.4 \%$ vs. $57.9 \%$ for those who had never been homeless; $P=0.01)$. Health care access covariates significantly associated with ever having received an influenza vaccination were health insurance status $(74.4 \%$ for those with Medicaid, $76.2 \%$ for those with Medicare, $52.6 \%$ for those with private insurance, and $65.5 \%$ for those with some other type of insurance vs. $43.4 \%$ for those with no insurance; $P<0.001$ ), receiving routine medical care $(69.4 \%$ vs. $43.3 \%$ for those who do not; $P<0.001)$, receiving health or social services from a government agency (69.2\% vs. $50.3 \%$ for those who had not; $P<0.001$ ), receiving health or social services from a community agency $(67.3 \%$ vs. $58.5 \%$ for those who had not; $P=0.018$ ), and having tested positive for HIV ( $90.9 \%$ vs. $65.4 \%$ for those who had tested negative and $46.8 \%$ for those who had never been tested; $P<0.001$ ). Among vaccination-related covariates, significantly associated with greater likelihood of having ever received an influenza vaccination was being interested in an influenza vaccination at the time of the survey ( $65.1 \%$ vs. $50.7 \%$ for those who were not; $P=0.001$ ), and reporting a medical condition, except for HIV, which would indicate vaccination $(63.9 \%$ for those who would be medically indicated for vaccination vs. $55.0 \%$ for those who would not; $P<0.001$ ).

Table 1 also shows the results of multivariate models of correlates of ever having had an influenza vaccination. In a multivariate logistic regression model, variables that were significantly associated with a greater likelihood of having ever had the influenza vaccine were: being in the 50-64 age group (adjusted odds ratio $(\mathrm{AOR})=1.86,95 \%$ Confidence Interval $(\mathrm{CI})=1.04-3.31)$, and receiving Medicaid $(\mathrm{AOR}=1.98,95 \% \mathrm{CI}=1.25-3.15)$. Variables significantly associated with a lower likelihood of having ever had an influenza vaccination were not receiving routine medical care $(\mathrm{AOR}=0.51,95 \% \mathrm{CI}=0.34-0.76)$ and having never been tested (AOR $=0.15,95 \% \mathrm{CI}=0.04-0.58)$, or tested negative (AOR $=0.26,95 \% \mathrm{CI}=0.72-0.97)$ for HIV. Unadjusted odds ratios are not shown.

Table 2 shows the bivariate correlates for having been vaccinated in the last year among those who have ever had an influenza vaccination (Fall 2003-Spring 2004) or before last year (prior to Fall 2003). The covariates significantly associated with having had an influenza vaccination in the past year were: receiving routine medical care $(56.4 \%$ vs. $33.3 \%$ for those who $\operatorname{did}$ not; $P=0.001)$, having ever injected drugs $(69.8 \%$ vs. $48.2 \%$ for those who had never; $P=0.002$ ), injecting drugs in the past 6 months ( $81.8 \%$ vs. $49.6 \%$ for those who did not; $p 0.003)$, testing positive for HIV ( $88.9 \%$ vs. $40.2 \%$ for never been tested and $51.7 \%$ for testing negative; $P<0.001$ ), and being interested in an influenza vaccination at the time of survey ( $54.6 \%$ vs. $38.5 \%$ for those who were not; $P=0.017$ ). In the multivariate logistic regression, the variables significantly associated with a lower likelihood of having had an influenza vaccination in the most recent year were not receiving routine medical care $(\mathrm{AOR}=0.48$, $95 \% \mathrm{CI}=0.26-0.88)$, report of no illicit drug injection within the past 6 months $(\mathrm{AOR}=0.17,95 \% \mathrm{CI}=0.04-0.80)$, and never being tested or having tested negative for HIV (AOR $=0.13,95 \%$ 
Table 3

Correlates of wanting influenza vaccination among hard-to-reach residents of East Harlem and the Bronx who have never previously received a flu vaccination ${ }^{\text {a }}$

\begin{tabular}{|c|c|c|c|c|c|c|}
\hline \multirow[t]{2}{*}{ Characteristic } & \multicolumn{2}{|c|}{$\begin{array}{l}\text { Interested } \\
\text { in flu vaccine }\end{array}$} & \multicolumn{2}{|c|}{$\begin{array}{l}\text { Not interested } \\
\text { in flu vaccine }\end{array}$} & \multirow[t]{2}{*}{$P$ value } & \multirow{2}{*}{$\begin{array}{l}\text { Unadjusted odds ratio } \\
95 \% \text { CI }\end{array}$} \\
\hline & $n$ & $\%$ & $n$ & $\%$ & & \\
\hline \multicolumn{7}{|l|}{ Age } \\
\hline 18 to 29 & 56 & 70.9 & 23 & 29.1 & \multirow[t]{5}{*}{0.2011} & 1 \\
\hline 30 to 39 & 68 & 81.9 & 15 & 18.1 & & $1.86(0.89,3.90)$ \\
\hline 40 to 49 & 45 & 66.2 & 23 & 33.8 & & $0.80(0.40,1.62)$ \\
\hline 50 to 64 & 24 & 77.4 & 7 & 22.6 & & $1.41(0.53,3.72)$ \\
\hline 65 and older & 7 & 63.6 & 4 & 36.4 & & $0.72(0.19,2.69)$ \\
\hline \multicolumn{7}{|l|}{ Gender } \\
\hline Male & 106 & 79.1 & 28 & 20.9 & \multirow[t]{2}{*}{0.04} & 1 \\
\hline Female & 94 & 68.1 & 44 & 31.9 & & $0.56(0.32,0.97)$ \\
\hline \multicolumn{7}{|l|}{ Racial/ethnic background } \\
\hline White & 2 & 22.2 & 7 & 77.8 & \multirow{4}{*}{0.0003} & 1 \\
\hline Hispanic or Latino & 167 & 79.1 & 44 & 20.9 & & $13.27(2.66,66.12)$ \\
\hline African-American & 26 & 61.9 & 16 & 38.1 & & $5.68(1.05,30.80)$ \\
\hline Other & 6 & 66.7 & 3 & 33.3 & & $6.99(0.86,56.83)$ \\
\hline \multicolumn{7}{|l|}{ Marital status } \\
\hline Single, never married & 98 & 74.2 & 34 & 25.8 & \multirow[t]{6}{*}{0.5186} & 1 \\
\hline Divorced & 16 & 66.7 & 8 & 33.3 & & $0.69(0.27,1.77)$ \\
\hline Separated & 14 & 60.9 & 9 & 39.1 & & $0.54(0.21,1.36)$ \\
\hline Widowed & 5 & 71.4 & 2 & 28.6 & & $0.87(0.16,4.68)$ \\
\hline Married or common law & 59 & 79.7 & 15 & 20.3 & & $1.37(0.69,2.72)$ \\
\hline Domestic partnership & 8 & 80.0 & 2 & 20.0 & & $1.39(0.28,6.86)$ \\
\hline \multicolumn{7}{|l|}{ Total legal income } \\
\hline No income & 78 & 81.3 & 18 & 18.8 & \multirow[t]{5}{*}{0.0342} & 1 \\
\hline$\$ 1$ to $\$ 4800 /$ year & 38 & 79.2 & 10 & 20.8 & & $0.88(0.37,2.08)$ \\
\hline$\$ 4801$ to $\$ 9600 /$ year & 40 & 70.2 & 17 & 29.8 & & $0.54(0.25,1.17)$ \\
\hline$\$ 9601 /$ year and up & 37 & 59.7 & 25 & 40.3 & & $0.34(0.17,0.70)$ \\
\hline Missing & 8 & 80.0 & 2 & 20.0 & & $0.92(0.18,4.72)$ \\
\hline \multicolumn{7}{|l|}{ Housing type } \\
\hline Homeless & 22 & 84.6 & 4 & 15.4 & \multirow[t]{4}{*}{0.4467} & 1 \\
\hline Transitional & 31 & 77.5 & 9 & 22.5 & & $0.63(0.17,2.29)$ \\
\hline Institutional & 4 & 66.7 & 2 & 33.3 & & $0.36(0.05,2.70)$ \\
\hline Stable & 138 & 71.1 & 56 & 28.9 & & $0.45(0.15,1.36)$ \\
\hline Ever been homeless & & & & & & \\
\hline Yes & 72 & 82.8 & 15 & 17.2 & 0.0191 & 1 \\
\hline No & 124 & 69.3 & 55 & 30.7 & & $0.47(0.25,0.89)$ \\
\hline Ever hungry in past 6 mon & & & & & & \\
\hline Yes & 69 & 80.2 & 17 & 19.8 & 0.1006 & 1 \\
\hline No & 131 & 70.8 & 54 & 29.2 & & $0.60(0.32,1.11)$ \\
\hline Health insurance status & & & & & & \\
\hline None & 104 & 81.3 & 24 & 18.8 & 0.0033 & 1 \\
\hline Medicaid & 55 & 72.4 & 21 & 27.6 & & $0.60(0.31,1.18)$ \\
\hline Medicare & 7 & 70.0 & 3 & 30.0 & & $0.54(0.13,2.24)$ \\
\hline Private insurance/HMO & 15 & 46.9 & 17 & 53.1 & & $0.20(0.09,0.46)$ \\
\hline Other & 18 & 75.0 & 6 & 25.0 & & $0.69(0.25,1.93)$ \\
\hline Receives routine medical & & & & & & \\
\hline Yes & 99 & 67.8 & 47 & 32.2 & 0.0259 & 1 \\
\hline No & 99 & 79.8 & 25 & 20.2 & & $1.88(1.07,3.29)$ \\
\hline Ever received health/socia & iment & & & & & \\
\hline Yes & 88 & 68.8 & 40 & 31.3 & 0.0921 & 1 \\
\hline No & 112 & 77.8 & 32 & 22.2 & & $1.59(0.93,2.74)$ \\
\hline Ever received health or so & mmu & & & & & \\
\hline Yes & 67 & 79.8 & 17 & 20.2 & 0.1138 & 1 \\
\hline No & 132 & 70.6 & 55 & 29.4 & & $0.61(0.33,1.13)$ \\
\hline Ever injected drugs & & & & & & \\
\hline Yes & 22 & 81.5 & 5 & 18.5 & 0.3332 & 1 \\
\hline No & 177 & 72.8 & 66 & 27.2 & & $0.61(0.22,1.68)$ \\
\hline
\end{tabular}


Table 3 (continued)

\begin{tabular}{|c|c|c|c|c|c|c|}
\hline \multirow[t]{2}{*}{ Characteristic } & \multicolumn{2}{|c|}{$\begin{array}{l}\text { Interested } \\
\text { in flu vaccine }\end{array}$} & \multicolumn{2}{|c|}{$\begin{array}{l}\text { Not interested } \\
\text { in flu vaccine }\end{array}$} & \multirow[t]{2}{*}{$P$ value } & \multirow{2}{*}{$\begin{array}{l}\text { Unadjusted odds ratio } \\
95 \% \mathrm{CI}\end{array}$} \\
\hline & $n$ & $\%$ & $n$ & $\%$ & & \\
\hline \multicolumn{7}{|c|}{ Injected drugs in the past 6 months } \\
\hline Yes & 14 & 82.4 & 3 & 17.6 & \multirow[t]{2}{*}{0.5721} & 1 \\
\hline No & 187 & 73.0 & 69 & 27.0 & & $0.58(0.16,2.08)$ \\
\hline \multicolumn{7}{|c|}{ Ever traded sex } \\
\hline Yes & 13 & 81.3 & 3 & 18.8 & \multirow[t]{2}{*}{0.571} & 1 \\
\hline No & 185 & 72.8 & 69 & 27.2 & & $0.62(0.17,2.24)$ \\
\hline \multicolumn{7}{|c|}{ Traded sex in the past 6 months } \\
\hline Yes & 5 & 83.3 & 1 & 16.7 & \multirow[t]{2}{*}{1} & 1 \\
\hline No & 196 & 73.4 & 71 & 26.6 & & $0.55(0.06,4.81)$ \\
\hline \multicolumn{7}{|c|}{ Ever had a hepatitis vaccine } \\
\hline Yes & 61 & 70.1 & 26 & 29.9 & \multirow[t]{2}{*}{0.3316} & 1 \\
\hline No & 131 & 75.7 & 42 & 24.3 & & $1.33(0.75,2.36)$ \\
\hline \multicolumn{7}{|l|}{ HIV status } \\
\hline Positive & 2 & 66.7 & 1 & 33.3 & \multirow{3}{*}{0.0701} & 1 \\
\hline Never tested & 84 & 81.6 & 19 & 18.4 & & $2.21(0.19,25.66)$ \\
\hline Negative & 108 & 68.8 & 49 & 31.2 & & $1.10(0.10,12.44)$ \\
\hline
\end{tabular}

a Due to missing values, the numbers in some of the cross tabulations presented in this table may not add up to the total number of participants in this table's subset.

$\mathrm{CI}=0.03-0.51$ and $\mathrm{AOR}=0.20,95 \% \mathrm{CI}=0.06-0.71$, respectively). Unadjusted odds ratios are not shown.

Table 3 shows the correlates of interest in receiving an influenza vaccination at the time of the survey among those who have never had an influenza vaccination $(N=273)$. Significant covariates were: being a racial minority $(79.1 \%$ for Hispanics/ Latinos, $61.9 \%$ for African-Americans, and $66.7 \%$ Other vs. $22.2 \%$ for Whites; $P=0.001$ ), having lower annual income (81.3\% of those with no income, $79.2 \%$ of those earning $\$ 1-$ $\$ 4800,70.2 \%$ of those earning $\$ 4801-\$ 9600$, and $59.7 \%$ for those earning $\$ 9601$ or more; $P=0.034)$, having ever been homeless $(82.8 \%$ vs. $69.3 \%$ of those who had not; $P=0.012)$, having no health insurance or government insurance $(81.3 \%$ for those with no insurance, $72.4 \%$ for those with Medicaid, and $70.0 \%$ for those with Medicare vs. $46.9 \%$ for those with private insurance; $P=0.003$ ), and not receiving routine medical care (79.8\% vs. $69.8 \%$ for those who did; $P=0.026)$.

Table 4 shows the correlates of the reasons respondents gave for why they were not interested in receiving an influenza vaccination, among those who were not interested in one at time of the survey $(N=113)$. Participants who had ever had an influenza vaccination were more likely to say that the vaccine is not safe $(24.4 \%)$ and that they hate injections $(26.7 \%)$ as the reason for their disinterest in a vaccination at the time of interview. Among those who had never had an influenza vaccination, the most likely reasons for lack of interest were that they were at low risk $(34.4 \%)$, and, similar to the previous group, that they disliked injections $(25.0 ; P=0.001)$.

\section{Discussion}

Among residents of eight disadvantaged neighborhoods in East Harlem and the Bronx, New York City, we found that $62 \%$ had received one influenza vaccination at least once in their lifetime. We found that persons who were less likely to have ever had an influenza vaccination were younger, had lower income, did not have health insurance, had no access to routine medical care, and were not receiving other health or social services. Determinants of receiving a recent influenza vaccination included having routine access to medical care, injection drug use, and HIV-positive serostatus. We found that those who wanted the vaccine at the time of the survey were more likely to be racial minorities, to have a lower annual income, to have a history of homelessness, and to lack a source of routine medical care.

Our findings are congruent with studies that have found that persons who are vaccinated are older, are more likely to have a higher rate of access to medical care, and have a higher number of annual physician visits (Nowalk et al., 2004; Wilson et al., 2002; Pena-Rey et al., 2004; Petersen et al., 1999; Nichol et al., 1992; Chapman and Coups, 1999; Carter et al., 1986). It is possible that this is the result of a greater likelihood, with age, of receiving care for chronic illness and being prioritized by caregivers for receipt of vaccine. We observed a lower likelihood of vaccination among those with no access to routine medical care. This observation contrasts with studies that suggest that lack of access to routine medical care is not a barrier to vaccination (Santibanez et al., 2002; Frank et al., 1985). However, most previous studies were conducted in elderly populations; this is in contrast to our sample in which fewer than $8 \%$ of respondents were over age 65 . Other work provides corroborating evidence that health care providers of hard-to-reach populations may be in a unique position to deliver vaccines to these groups. Seventy-one percent of participants in one study of intravenous drug-users said they would have accepted a vaccine if asked (Seal et al., 2000). Other studies confirm that the recommendation of a health professional is the greatest single determinant of whether people, from a variety of backgrounds, are vaccinated (Duclos and Hatcher, 1993; Nowalk et al., 2004; Lashuay et al., 2000; Chapman and Coups, 1999; Wilson et al., 2002; Figaro and Belue, 2005). Given that $70.3 \%$ of 
Table 4

Correlates of reasons ${ }^{\mathrm{a}}$ for not wanting influenza vaccination at the time of survey among residents of East Harlem and the Bronx ${ }^{\mathrm{b}, \mathrm{c}}$

\begin{tabular}{|c|c|c|c|c|c|c|c|c|c|}
\hline \multirow[t]{2}{*}{ Characteristic } & \multicolumn{2}{|c|}{$\begin{array}{l}\text { Not interested, } \\
\text { not safe }\end{array}$} & \multicolumn{2}{|c|}{$\begin{array}{l}\text { Not interested, } \\
\text { hate injections }\end{array}$} & \multicolumn{2}{|c|}{$\begin{array}{l}\text { Not interested, } \\
\text { medical reason }\end{array}$} & \multicolumn{2}{|c|}{$\begin{array}{l}\text { Not interested, } \\
\text { low risk }\end{array}$} & \multirow[t]{2}{*}{$P$ value } \\
\hline & $n$ & $\%$ & $n$ & $\%$ & $n$ & $\%$ & $n$ & $\%$ & \\
\hline \multicolumn{10}{|l|}{ Age } \\
\hline 18 to 29 & 8 & 23.5 & 11 & 32.4 & 1 & 2.9 & 7 & 20.6 & \multirow[t]{5}{*}{0.4385} \\
\hline 30 to 39 & 3 & 13.0 & 5 & 21.7 & 3 & 13.0 & 5 & 21.7 & \\
\hline 40 to 49 & 9 & 25.0 & 7 & 19.4 & 6 & 16.7 & 10 & 27.8 & \\
\hline 50 to 64 & 2 & 14.3 & 2 & 14.3 & 4 & 28.6 & 2 & 14.3 & \\
\hline 65 and older & 1 & 16.7 & 3 & 50.0 & 0 & 0.0 & 1 & 16.7 & \\
\hline \multicolumn{10}{|l|}{ Gender } \\
\hline Male & 7 & 18.9 & 6 & 16.2 & 6 & 16.2 & 9 & 24.3 & \multirow[t]{2}{*}{0.4918} \\
\hline Female & 16 & 21.1 & 22 & 28.9 & 8 & 10.5 & 16 & 21.1 & \\
\hline \multicolumn{10}{|l|}{ Racial/ethnic background } \\
\hline Hispanic or Latino & 16 & 21.9 & 18 & 24.7 & 12 & 16.4 & 13 & 17.8 & \multirow[t]{4}{*}{0.2189} \\
\hline African-American & 4 & 14.8 & 9 & 33.3 & 2 & 7.4 & 7 & 25.9 & \\
\hline White & 1 & 12.5 & 0 & 0.0 & 0 & 0.0 & 4 & 50.0 & \\
\hline Other & 0 & 0.0 & 1 & 50.0 & 0 & 0.0 & 1 & 50.0 & \\
\hline \multicolumn{10}{|l|}{ Total legal income } \\
\hline No income & 5 & 21.7 & 6 & 26.1 & 2 & 8.7 & 7 & 30.4 & \multirow[t]{5}{*}{0.169} \\
\hline$\$ 1$ to $\$ 4800 /$ year & 5 & 27.8 & 5 & 27.8 & 3 & 16.7 & 0 & 0.0 & \\
\hline$\$ 4801$ to $\$ 9600 /$ year & 6 & 22.2 & 5 & 18.5 & 4 & 14.8 & 8 & 29.6 & \\
\hline$\$ 9601 /$ year and up & 7 & 17.5 & 8 & 20.0 & 5 & 12.5 & 10 & 25.0 & \\
\hline Missing & 0 & 0.0 & 4 & 80.0 & 0 & 0.0 & 0 & 0.0 & \\
\hline \multicolumn{10}{|l|}{ Ever been homeless } \\
\hline Yes & 9 & 28.1 & 7 & 21.9 & 3 & 9.4 & 4 & 12.5 & \multirow[t]{2}{*}{0.3493} \\
\hline No & 14 & 17.9 & 20 & 25.6 & 11 & 14.1 & 20 & 25.6 & \\
\hline \multicolumn{10}{|l|}{ Ever hungry in past 6 months } \\
\hline Yes & 5 & 20.0 & 5 & 20.0 & 4 & 16.0 & 6 & 24.0 & \multirow[t]{2}{*}{0.8263} \\
\hline No & 18 & 20.9 & 23 & 26.7 & 9 & 10.5 & 19 & 22.1 & \\
\hline \multicolumn{10}{|l|}{ Health insurance status } \\
\hline None & 8 & 25.0 & 8 & 25.0 & 5 & 15.6 & 7 & 21.9 & \multirow[t]{5}{*}{0.2313} \\
\hline Medicaid & 9 & 23.1 & 9 & 23.1 & 4 & 10.3 & 7 & 17.9 & \\
\hline Medicare & 0 & 0.0 & 0 & 0.0 & 3 & 50.0 & 1 & 16.7 & \\
\hline Private insurance/HMO & 4 & 18.2 & 8 & 36.4 & 1 & 4.5 & 5 & 22.7 & \\
\hline Other & 2 & 15.4 & 3 & 23.1 & 1 & 7.7 & 4 & 30.8 & \\
\hline \multicolumn{10}{|l|}{ Ever had a flu vaccine } \\
\hline Yes & 11 & 24.4 & 12 & 26.7 & 9 & 20.0 & 2 & 4.4 & 0.0011 \\
\hline No & 10 & 15.6 & 16 & 25.0 & 4 & 6.3 & 22 & 34.4 & \\
\hline Do not know & 2 & 100.0 & 0 & 0.0 & 0 & 0.0 & 0 & 0.0 & \\
\hline When received last flu vaccine & & & & & & & & & \\
\hline Never received one & 10 & 15.6 & 16 & 25.0 & 4 & 6.3 & 22 & 34.4 & 0.0029 \\
\hline This year (Fall, 2003-Spring, 2004) & 4 & 25.0 & 5 & 31.3 & 1 & 6.3 & 2 & 12.5 & \\
\hline Before this year (pre-Fall 03) & 7 & 30.4 & 6 & 26.1 & 7 & 30.4 & 0 & 0.0 & \\
\hline HIV status & & & & & & & & & \\
\hline Never tested & 5 & 20.8 & 7 & 29.2 & 2 & 8.3 & 7 & 29.2 & 0.6829 \\
\hline Positive & 0 & 0.0 & 1 & 50.0 & 1 & 50.0 & 0 & 0.0 & \\
\hline Negative & 18 & 21.4 & 19 & 22.6 & 11 & 13.1 & 16 & 19.0 & \\
\hline
\end{tabular}

${ }^{\text {a }}$ Participants could only select one reason why they did not want a flu vaccine.

b Due to missing values, the numbers in some of the cross tabulations presented in this table may not add up to the total number of participants in this table's subset.

c Percentages presented are row percents.

the population studied reported routine access to medical care, this venue for increasing influenza vaccination should be underscored.

Our findings concur with those who have found that the unvaccinated, and those who do not want a vaccination, often think they are at low risk, particularly those at high risk of morbidity and mortality due to influenza (Santibanez et al., 2002; Seal et al., 2000; Centers for Disease Control, 1997). Our findings also agree with previous observations that persons who believe that the influenza vaccination is not safe are more likely never to have been vaccinated, or at least not to have been vaccinated in the past 12 months
(Figaro and Belue, 2005; Wilson et al., 2002). Congruent with previous work, we found that mistrust of the health care system or providers of government or community services was not a substantial barrier to immunization (Santibanez et al., 2002). Most participants believed these groups have their best interests in mind. One factor not assessed by our study that could be a barrier to vaccination was whether respondents were ambulatory and able to get to the point of vaccine delivery. This is a possible avenue for future research, particularly for members of this population who are elderly or disabled. 
Our data suggest that one key method to increase influenza vaccination rates in disadvantaged urban populations is through affiliation with health and social services. Innovative studies that have linked influenza vaccine delivery with less traditional services have shown promise in delivering vaccine to hard-to-reach populations. Some pilot projects have shown success in vaccinating hard-to-reach populations through harm reduction sites, emergency rooms, and other venues (Grau et al., 2002; Stancliff et al., 2000; Slobodkin et al., 1998; Solomon et al., 1991). Changing attitudes about side effects of influenza vaccination has been shown to improve vaccination rates, as has offering different forms of vaccine administration, such as a nasal spray, to those who dislike injections (Buchner et al., 1985). Some studies have shown that African-Americans who were able to access primary care received preventive services at rates equal to or greater than white patients, including immunizations (Williams et al., 2001; Wright et al., 2000).

Our results must be interpreted with caution. Because we relied on self-reported data, we have no way of confirming if the reports of receiving influenza vaccination, or other variables, were accurate. Also, it is possible that these results are not generalizable to other hard-to-reach populations in the city, with differing demographic compositions, or to cities other than New York City. Our study considered reasons for not wanting an influenza vaccination; however, we did not consider reasons why persons may want influenza vaccination. Since no one really knows the true make-up of this hard-to-reach population, it is difficult to say if our sample was representative of that population. It is also difficult to say if those who agreed to participate in our survey differed from those who refused. However, based on our conclusions, and the validation of our methods in other studies (Diaz et al., 2001a,b), we feel our results stand. Another possible limitation of our study is the relatively low number of white subjects $(N=27,3.6 \%)$. Because of this, one must be careful in drawing conclusions about minority subjects relative to whites.

Low vaccination rates may be attributable to poor communication to populations of risk regarding both the risks of influenza, and the side effects of the vaccination. In one study of the elderly, half received all their health information from their physician and half from books, television, the Internet, and other media, suggesting an important role for dissemination vaccination-related information through less traditional outlets (Santibanez et al., 2002).

Our findings suggest that connecting members of hard-to-reach populations to government or community social services may be one way to greatly improve influenza vaccination rates. The fact that more than three quarters of survey respondents were interested in receiving influenza vaccine at the time of survey, whether connected to social services or not, indicates it may be possible to conduct well-received influenza vaccination campaigns in this population. A high reported rate of routine access to medical care among the population studied implies that health care providers may be the best route to increasing influenza vaccination in this group. Our findings suggest that there is an unmet need for influenza vaccine particularly among those persons who have been homeless, uninsured, and receive little or no income.

\section{Acknowledgments}

This work was funded by grants DA-06534, DA-12801-S1, and R01-DA-017642 from the National Institutes of Health; grants DA13146 and DA12801 from the National Institute on Drug Abuse; and a grant from the Merck Foundation. This project was initiated and analyzed by the investigator. Members of the VIVA working group who supervised this project include Dr. Ann Boyer, Dr. Robert Brackbill, Jose Caraballo, Gail Love, Karyn London, Pat Monahan, Dr. Sharon Stancliff, Brian Brown, and Dr Linda Weiss.

\section{References}

Barker, W.H., Mullooly, J.P., 1980. Influenza vaccination of elderly persons. Reduction of pneumonia and influenza hospitalizations and deaths. Journal of the American Medical Association 244, 2547-2549.

Bridges, C.B., Thompson, W.W., Meltzer, M.I., et al., 2000. Effectiveness and cost-benefit of influenza vaccination of healthy working adults. Journal of the American Medical Association 284 (13), 1655-1663.

Buchner, D.M., Carter, W.B., Inui, T.S., 1985. The relationship of attitude changes to compliance with influenza immunization: a prospective study. Medical Care 23, 771-779.

Carter, W.B., Beach, L.R., Inui, T.S., Kirscht, J.P., Prodzinski, J.C., 1986. Developing and testing a decision model for predicting influenza vaccination compliance. Health Services Research 20 (6, Pt. 2), 897-932.

Centers for Disease Control, 1997. Vaccination levels among Hispanics and non-Hispanic whites aged $\geq 65$ years: Los Angeles County, California, 1996. Morbidity and Mortality Weekly Report 46 (49), 1165-1168.

Centers for Disease Control, 2005. Prevention and control of influenza: recommendations of the advisory committee on immunizations practices. Morbidity and Mortality Weekly Report 54 (Early Release).

Chapman, G.B., Coups, E.J., 1999. Predictors of influenza vaccine acceptance among health adults. Preventive Medicine 29, 249-262.

Collins, S.C., Hall, A., Neuhaus, C., 1999. US Minority Health: A Chartbook. The Commonwealth Fund, New York.

Couch, R.B., 1993. Advances in influenza virus vaccine research. Annals of the New York Academy of Sciences 685, 803-812.

Department of Health and Human Services, 2000. Healthy People 2010. http:// www.healthypeople.gov. Accessed February 222005.

Department of Health and Human Services, 2004. Pandemic Influenza Response and Preparedness Plan. August, http://www.hhs.gov/nvpo/pandemicplan/. Accessed September 42004.

Diaz, T., Des Jarlais, D.C., Vlahov, D., et al., 2001a. Factors associated with prevalence of hepatitis $\mathrm{C}$ : differences among young adult injection drug users in lower and upper Manhattan, New York City. American Journal of Public Health 91 (1), 23-30.

Diaz, T., Vlahov, D., Greenberg, B., Cuevas, Y., Garfein, R., 2001b. Sexual Orientation and HIV infection prevalence among young Latino injection drug users in Harlem. Journal of Women's Health and Gender-Based Medicine 10 (4), 371-380.

Duclos, P., Hatcher, J., 1993. Epidemiology of influenza vaccination in Canada. Canadian Journal of Public Health 84 (5), 311-315.

Egede, L.E., Zheng, D., 2003. Racial/ethnic differences in influenza vaccination coverage in high-risk adults. American Journal of Public Health 93 (12), 2074-2078.

Fedson, D.S., 1987. Influenza prevention and control: past practices and future prospects. American Journal of Medicine 82, 42-47.

Figaro, M.K., Belue, R., 2005. Prevalence of influenza vaccination in a high-risk population: impact of age and race. Journal of Ambulatory Care Management 28 (1), 24-29.

Frank, J.W., Henderson, M., McMurray, L., 1985. Influenza vaccination in the elderly: 1. Determinants of acceptance. Canadian Medical Association Journal 132 (4), 371-375. 
Grau, L.E., Arevalo, S., Catchpool, C., Heimer, R., 2002. Expanding harm reduction services through a wound and abscess clinic. American Journal of Public Health 92 (12), 1915-1917.

Hargraves, L.J., 2001. Race, ethnicity and preventive services: no gains for Hispanics. Issue Brief: Center for Studying Health System Change 34, 1-4.

Lashuay, N., Tjoa, T., Zuniga de Nuncio, M.L., Franklin, M., Elder, J., Jones, M., 2000. Exposure to immunization media messages among African American parents. Preventive Medicine 31, 522-528.

Marin, M.G., Johanson, W.G., Salas-Lopez, D., 2002. Influenza vaccination among minority populations in the United States. Preventive Medicine 34, 235-241.

Mullooly, J.P., Bennett, M.D., Hornbrook, M.C., et al., 1994. Influenza vaccination programs for elderly persons: cost-effectiveness in a health maintenance organization. Annals of Internal Medicine 121, 947-952.

Nichol, K.L., Lofgren, R.P., Gapinski, J., et al., 1992. Influenza vaccination: knowledge, attitudes, and behavior among high-risk outpatients. Archives of Internal Medicine 152 (1), 106-110.

Nichol, K.L., Lind, A., Margolis, K.L., et al., 1995. The effectiveness of vaccination against influenza in healthy, working adults. The New England Journal of Medicine 333 (14), 889-893.

Nowalk, M.P., Zimmerman, R.K., Shen, S., Jewell, I.K., Raymund, M., et al., 2004. Barriers to pneumococcal and influenza vaccination in older community-dwelling adults (2000-2001). Journal of the American Geriatrics Society 52, 25-30.

Ompad, D.C., Galea, S., Fuller, C.M., Phelan, D., Vlahov, D., 2004. Club drug use among minority substance users in New York City. Journal of Psychoactive Drugs 36 (3), 397-399.

Ostbye, T., Taylor, D.H., Lee, A.M., Greenberg, G., van Scoyoc, L., 2003. Racial differences in influenza vaccination among older Americans 19962000: longitudinal analysis of the Health and Retirement Study (HRS) and the Asset and Health Dynamics Amongst the Oldest Old (AHEAD) survey. BioMed Central Public Health 3, 41-51.

Pena-Rey, I., Perez-Farinos, N., Sarria-Santamera, A., 2004. Factors associated with influenza vaccination among elderly Spanish women. Public Health 118 (8), 582-587.

Petersen, R.L., Saag, K., Wallace, R.B., Doebbeling, B.N., 1999. Influenza and Pneumococcal vaccine receipt in older persons with chronic disease. Medical Care 37, 502-509.
Santibanez, T.A., Nowalk, M.P., Zimmerman, R.K., Jewell, I.K., Bardella, I.J., Wilson, S.A., Terry, M.A., 2002. Knowledge and beliefs about influenza, pneumococcal disease and immunizations among older people. Journal of the American Geriatric Society 50, 1711-1716.

Seal, K.H., Edlin, B.R., Ochoa, K.C., Tulsky, J.P., Moss, A.R., Hahn, J.A., 2000 Risk of hepatitis B infection among young injection drug users in San Francisco: opportunities for intervention. Western Journal of Medicine 172 16-20.

Slobodkin, D., Kitlas, J., Zielske, P., 1998. Opportunities not missed-systematic influenza and pneumococcal immunization in a public inner-city emergency department. Vaccine 16 (19), 1795-1802.

Solomon, L., Frank, R., Vlahov, D., Astemborski, J., 1991. Utilization of health services in a cohort of intravenous drug users with known HIV-1 serostatus. American Journal of Public Health 81 (10), 1285-1290.

Stancliff, S., Salomon, N., Perlman, D.C., Russell, P.C., 2000. Provision of influenza and pneumococcal vaccines to injection drug users at a syringe exchange. Journal of Substance Abuse Treatment 18, 263-265.

Task Force on Community Preventive Services, 2000. Recommendations regarding interventions to improve vaccination coverage in children, adolescents, and adults. American Journal of Preventive Medicine 18, 92-96.

Thompson, W.W., Shay, D.K., Weintraub, E., et al., 2003. Mortality associated with influenza and respiratory syncytial virus in the United States. Journal of the American Medical Association 289, 179-186.

Williams, R.L., Flocke, S.A., Stange, K.C., 2001. Race and preventive services delivery among black patients and white patients seen in primary care. Medical Care 11 (39), 1260-1267.

Wilson, D., Lester, R., Taylor, A., et al., 2002. Prevalence of influenza immunisation in Australia and suggestions for future targeting of campaigns. Sozial- und Praventivmedizin 47 (2), 91-99.

Wright, P.J., Fortinsky, R.H., Covinsky, K.E., Anderson, P.A., Landefeld, C.S., 2000. Delivery of preventive services to older black patients using neighborhood health centers. Journal of the American Geriatric Society 48 (2), 124-130.

Zimmerman, R.K., Santibanez, T.A., Janosky, J.E., et al., 2003. What affects influenza vaccination rates among older patients? An analysis from innercity, suburban, rural, and Veterans Affairs practices. The American Journal of Medicine 114 (1), 31-38. 